\title{
AVALIAÇÃO DE MARCAS DE LUXO: UM ESTUDO EXPERIMENTAL COM DOIS FATORES MODERADORES
}

\section{Andrea Kassouf Pizzinatto}

Doutora em Administração pela Universidade Nove de Julho - UNINOVE, São Paulo (Brasil) Professora de Marketing pela Universidade Metodista de Piracicaba - UNIMEP, São Paulo (Brasil). E-mail: marketingandrea@yahoo.com.br

\section{Evandro Luiz Lopes}

Doutor em Administração pela Universidade Nove de Julho - UNINOVE, São Paulo (Brasil) Professor do Mestrado e Doutorado em Administração de Empresas pela Universidade Nove de Julho - PPGA/UNINOVE, São Paulo (Brasil). E-mail: elldijo@uol.com.br

\section{Suzane Strehlau}

Doutorado em Administração de Empresas pela Fundação Getulio Vargas - FGV, São Paulo (Brasil). Professora do Mestrado em Administração pela Universidade Ceuma - UNICEUMA, Maranhão (Brasil). E-mail: strehlau@uol.com.br

\section{Nadia Kassouf Pizzinatto}

Doutorado em Administração de Empresas pela Fundação Getulio Vargas - FGV, São Paulo (Brasil). Professora do Mestrado Profissional e Doutorado em Administração pela Universidade Metodista de Piracicaba - UNIMEP, São Paulo (Brasil). E-mail: nkp@gmail.com.br 


\title{
AVALIAÇÃO DE MARCAS DE LUXO: UM ESTUDO EXPERIMENTAL COM DOIS FATORES MODERADORES
}

\section{RESUMO}

O marketing de marcas de luxo apresenta algumas particularidades em relação ao utilizado em outros mercados. O objetivo principal deste estudo é identificar os efeitos do endossamento de celebridades e do país de origem na avaliação de marcas de luxo. Para tanto, realizaram-se dois experimentos, nos quais as variáveis foram manipuladas por meio de anúncios publicitários desenvolvidos para este fim. Os resultados indicam que a) a avaliação da marca de luxo não é favorecida pela utilização de endossamentos, mesmo de celebridades, e b) existem indícios quanto ao efeito país de origem na moderação da avaliação realizada pelos consumidores em determinadas circunstâncias.

Palavras-chave: Marcas. Marcas de luxo. Endossador. Efeito país de origem.

\begin{abstract}
The luxury brand marketing, differently from conventional marketing and branding, has specific characteristics. The main objective of this study is to identify the effects of the endorsement of celebrities and country of origin in the luxury brands evaluation. So the field research was conducted with two experiments, involving manipulation of variables through printed advertisings developed especially for this study. The results indicate that luxury brand evaluation is not affected by the use of endorsers, even celebrities endorsers. Also we verified that the country of origin may influence the customers brand evaluation in some circumstances.
\end{abstract}

Keywords: Brands. Luxury brands. Endorser. Country of origin effect. 


\section{INTRODUÇÃO}

A demanda por bens de luxo cresce fortemente em economias em desenvolvimento, especialmente na Ásia e no Brasil, devido a um acúmulo de demanda reprimida e enriquecimento de uma parcela da população (Strehlau, 2008). Esse fato é particularmente importante para as empresas, pois a economia de países desenvolvidos atravessa um momento de crise. A estratégia do marketing de luxo é usada por diferentes indústrias, não somente por aquelas que vendem produtos de luxo, mas também por outras que se propõem a entregar mais valor por menos dinheiro (Wiedmann \& Nadine, 2013).

A gestão das ferramentas de marketing de luxo difere daquela praticada no mercado de massa (ou não luxo). O papel da propaganda, por exemplo, não é necessariamente estimular a venda direta para o público em geral, mas sim tentar estimular o desejo, tanto dentro quanto fora de seu target (Kapferer \& Bastien, 2009a; Kapferer \& Vincent, 2009b; Kapferer \& Valette Florence, 2016).

Algumas empresas optaram por trabalhar sua estratégia nas regras do luxo (herança, autenticidade e valor de exclusividade), focando seus esforços apenas no posicionamento de marcas premium - como a montadora GM com o automóvel Saab (Bastien \& Kapferer, 2013; Kapferer \& Valette Florence, 2016) - enquanto outras adotam práticas utilizadas no mercado de massa.

Contudo, foi somente na década de 1970 que marcas de luxo experimentaram a estratégia de endossamento por celebridades. Nessa época, as marcas Versace e Giorgio Armani começaram a usar fotógrafos e modelos famosos (Thomas, 2008). A Calvin Klein, por exemplo, contratou o fotógrafo Richard Avedon e a atriz americana Brooke Shields para sua companha publicitária do início dos anos de 1980, apresentando o slogan "Não há nada entre meu jeans Calvin e eu".

Por um lado, a corrente teórica liderada por Kapferer preconiza que a humanização, em especial com o uso de personalidades célebres, deve ser evitada nas propagandas de marcas de luxo, pois estas devem ser desejadas por si só e não por serem utilizadas por alguém célebre. Por outro lado, o uso de celebridades para endossar 
marcas de luxo beneficia o desempenho da comercialização dos produtos (Okonkwo, 2007), porque isso aumentaria a consciência de marca e auxiliaria no posicionamento e na sustentação da memória.

No mercado de massa, o uso de celebridades como endossadoras de uma marca é reconhecido como uma ferramenta potencialmente eficiente na comunicação (Liu, Huang \& Minghua, 2007; Das, Vermeulen, Laagland \& Postma, 2010 e Wang \& Lin, 2011). Se o endossador é congruente com o produto, deve influenciar positivamente o consumidor pelo processo de internalização, levando-o a desenvolver uma atitude favorável em relação ao produto, consistente com seu sistema de valores (Wang \& Lin, 2011; Liu et al., 2016).

As marcas de luxo, apesar de estarem atreladas à sua nacionalidade, por serem mais relevantes, sofrem menos o efeito país de origem (Aiello Aiello, Donvito, Godey, Pederzoli, Wiedmann, Hennigs \& Singh, 2009; Shukla, Singh, \& Banerjee, 2015). Já no mercado de massa, o efeito país de origem deve ser entendido como um possível moderador da avaliação do consumidor, pois a imagem que este tem em relação ao país no qual o produto foi fabricado tem um efeito cognitivo que pode influenciar a avaliação do produto em si (Chyssochoidis, Krystallis \& Perreas, 2007; Fetscherin \& Toncar, 2009).

Diante desse cenário, o objetivo deste estudo é identificar os efeitos do endossamento de celebridades e do país de origem na avaliação de marcas de luxo. Para tanto, realizamos dois experimentos, nos quais as variáveis foram manipuladas por meio de anúncios publicitários desenvolvidos para este fim, como será descrito nas próximas seções.

\section{ARCABOUÇO TEÓRICO}

Os conceitos centrais de marcas de luxo e de endossamento por celebridades são abordados neste tópico.

\section{Marcas de luxo}

O conceito de luxo liga-se tanto a objetos quanto a códigos, comportamentos, valores estéticos e estilo de vida (Casterède, 2005; Liu et al., 2016), é de natureza dinâmica e pode se materializar no objeto, na marca ou no serviço. O luxo existe em função da distinção social, do conhecimento que embasa o consumo e das suas 
representações. O consumidor transforma-se com o tempo. Assim, o que era conhecido como uma distinção acaba por tornar-se comum. Não são convencionados os limites do mercado de luxo, ou seja, quando uma marca pode ser considerada de luxo (Strehlau, 2008), porém é possível identificar diversos níveis de luxo (Lipovetsky \& Roux, 2005).

Os produtos de luxo começaram a ser conhecidos pelo nome do seu fabricante. A aplicação de marcas é interessante para o marketing, a fim de que o consumidor possa identificá-la e que esse nome se diferencie dos demais. O luxo fica cada vez menos presente no objeto, em sua categoria funcional e mais presente na marca e sua simbologia (Bellaiche, Mei-Pochtler \& Hanisch, 2010; De Toni et al., 2014; Liu et al., 2016).

O interesse do consumidor é potencializado pela marca do fabricante do produto (Das et al., 2010), pois as marcas de luxo [ML, desse ponto em diante] representam mais do que tradicionalmente qualidade e confiabilidade. Elas oferecem aos possuidores de seus produtos a oportunidade de autoexpressão, autorrealização e identidade própria (Das et al., 2010; Wang \& Lin, 2011).

Os produtos de ML são provavelmente os mais representativos da complexidade da escolha de um objeto e de um ato de compra (Allèrés, 2006, p.75), dado que seus compradores apresentam "ao mesmo tempo, todos os fatores mais racionais da compra (qualidade e originalidade) e os mais irracionais (procura de distinção, gosto pelos objetos da marca)". Além disso, existem evidências de que o consumidor adquire as ML para pertencer a determinados grupos de aspiração (Goldsmith \& Clark, 2008; Hennigs et al. 2016). Desse modo, há o entendimento de que os produtos de ML favorecem a obtenção de estima e de distinção, conferem originalidade, geram admiração e servem como símbolo de poder e ostentação (Allèrés, 2006; Goldsmith \& Clark, 2008; Strehlau, 2008; Christodoulides, Michaelidou \& Li, 2009; De Toni et al., 2014; Hennigs et al. 2016; Kapferer \& Valette Florence, 2016).

Ocasionalmente, uma marca pode se autoproclamar luxuosa e a empresa pode se utilizar dessa estratégia no mercado de produção de massa. O mercado não é estático, as marcas podem migrar segundo a percepção do consumidor, que pode considerá-las mais ou menos luxuosas (Strehlau, 2008). Assim, Castarède (2005) conceitua ML como aquelas que podem justificar, ao longo do tempo, um preço elevado, ou seja, superior a produtos com funcionalidades tangíveis comparáveis.

As ML evocam exclusividade, identidade da marca bem conhecida, notoriedade e qualidade. Também podem ser definidas como aquelas cuja qualidade é mais alta do Revista de Gestão e Secretariado-GeSec, São Paulo, v. 7, n. 3, p 96-122, set./dez. 2016. 
que a média de mercado e cujos preços são significativamente maiores do que os praticados por marcas similares (Vigneron \& Johnson, 2004; Strehlau \& Huertas, 2006; Sung et al., 2015).

Ao adquirir produtos de ML, o consumidor procura distinguir-se dos demais, buscando o atributo da exclusividade (uma das características dessas marcas), fenômeno denominado Consumer Need for Uniqueness. O produto de ML assume um papel no sistema de influências interpessoais e sociais já que permite demonstrar que um indivíduo possui objetos reconhecidos e desejados, que utiliza produtos raros e que pode deles dispor da forma como quiser (Strehlau \& Huertas, 2006; Goldsmith \& Clark, 2008; Hennigs et al. 2016).

O estudo de Vigneron e Johnson (2004) separa ML das marcas de não luxo por cinco dimensões: notoriedade, singularidade, qualidade, hedonismo e extensão do ser. $\mathrm{Na}$ verdade, existem marcas que podem ser de luxo em determinada categoria e não luxo em outra categoria. Existe também a distinção entre marcas associadas a um grau maior de sofisticação, estando outras relacionadas a um baixo grau de sofisticação. Uma marca pode ser definida como de luxo, mas nem todas as ML podem ser consideradas iguais, sendo que algumas têm maior sofisticação percebida que outras. Assim também uma marca pode ter maior sofisticação percebida em uma categoria de produto e menor em outra (Vigneron \& Johnson, 2004).

O marketing das ML tem se tornado uma tarefa cada vez mais complexa, pois, além de transmitir uma imagem de qualidade, desempenho e autenticidade, a marca deve vender uma experiência relacionada com o estilo de vida dos consumidores. Novos enfoques de marketing para as ML veem os consumidores como seres emocionais, em busca de experiências prazerosas, e não apenas como decisores, racionais focados nas características e benefícios dos produtos, tal como preconizava a visão tradicional (Atwal \& Williams, 2009; Sung et al., 2015).

Marcas frequentemente têm funções que ultrapassam a simples utilidade ou necessidade. Os consumidores podem adquirir produtos que representem sua identidade social. As marcas podem também afetar diferentemente a impressão das pessoas. Isso indica que as marcas fazem uma interação social com os consumidores: há aqueles que as utilizam como extensão de sua personalidade, da mesma forma como há os que o fazem para impressionar os outros (Das et al., 2010). Os produtos de ML têm intensa carga simbólica e emocional. Admitindo que os objetos luxuosos expressem os desejos e emoções humanos, por meio deles pode-se conhecer um pouco sobre os valores, 
crenças e atitudes dos consumidores (Galhanone, 2008; Husic \& Cicic, 2008; Shukla, Singh \& Banerjee, 2015).

O processo pelo qual o consumidor efetua as compras de tais marcas ainda é enigmático (Dubois \& Paternault, 1995). Parece particularmente difícil explicar e prever as condições e quais sonhos do consumidor emergirão e quais se materializarão em atos de compra (Dubois \& Paternault, 1995; Van Osselaer \& Janiszewski, 2001).

Entre as ML há diferentes graus de prestígio ou, em outras palavras, as dimensões de luxo percebidas são diferentes. Para avaliar essas diferenças, Vigneron e Johnson (2004) desenvolveram a escala Brand Luxury Index (BLI), que depois foi testada por Christodoulides e Michaelidou (2009) e Strehlau, Lopes e Freire (2012). Para se evitar essa zona cinzenta de marcas que não estão claramente operando no mercado de luxo, optou-se por pesquisar os extremos: as marcas claramente de luxo e também as de não luxo.

\section{Endossamento por celebridades}

Os gestores de marcas têm constantemente buscado um mix de marketing e conteúdo ideal para alcançar e influenciar consumidores na decisão de compra. Convencionalmente, um anúncio persuasivo deve conter argumentos consistentes; entretanto, os gestores têm enfrentado o problema de o consumidor não assimilar as informações nele contidas, em virtude do excesso de comunicação. Dessa forma, alguns gestores têm se utilizado de endossadores no anúncio publicitário para agregar reputação e credibilidade ao produto (Wang \& Lin, 2011).

Liu, Huang e Minghua (2007) mencionam que, tipicamente, existem quatro tipos de endossadores: celebridades, CEOs (Chief Executive Officers - Diretores Executivos) , especialistas e typical consumers. Os endossadores serão persuasivos ao consumidor de maneiras diferentes, dependendo do tipo de produto e do grau de envolvimento do consumidor. $\mathrm{O}$ endossador especialista representa fonte de credibilidade, confiança e, portanto, será persuasivo, segundo a literatura da psicologia social. Dessa forma, o endossador cujo apelo maior é a atratividade será persuasivo em função da familiaridade, simpatia, identificação pessoal do consumidor. Ainda segundo os autores, a estratégia do endossador é uma das mais populares práticas de marketing para as empresas. 
Uma parceria bem-sucedida com um endossador pode aumentar a intenção de compra do consumidor e a preferência pela marca, direta ou indiretamente. Endossadores com alta credibilidade, como especialistas, ou atratividade, como celebridades ou modelos, podem afetar significantemente a intenção de compra (Liu, Huang \& Minghua, 2007).

As marcas representam mais do que as tradicionalmente esperadas qualidade e confiabilidade (Das et al., 2010). Elas se alocam na mente das pessoas e lhes oferecem oportunidade de autoexpressão, autorrealização e identidade própria. Esse efeito é particularmente forte nas ML e o uso da celebridade como endossador da marca é reconhecido como uma ferramenta potencialmente eficiente na comunicação (Liu, Huang \& Minghua, 2007; Carroll, 2009). Carroll (2009) acredita que a estratégia de endosso produz impacto maior quando feita por celebridades, comparada com aquela que utiliza endossadores não célebres, ainda que altamente atraentes.

Endossadores altamente atraentes, ao contrário daqueles de baixa atratividade física, deverão despertar emoções positivas nos consumidores, as quais devem ser transferidas para a marca ou produto, e também influenciar na maior intenção de compra (Micu, Coulter \& Price, 2009; Soh, Reid \& King, 2009)

Micu, Coulter e Price (2009) e Das et al. (2010) sinalizam que, à primeira vista, a marca deveria influenciar positivamente as impressões a respeito de quem as usa, ou seja, os indivíduos que possuem produtos de marcas de luxo deveriam ser admirados. Entretanto, os autores questionam se a personalidade que figura na comunicação da marca pode ter influência negativa nessa percepção, o que poderia acontecer, por exemplo, caso houvesse uma incompatibilidade entre a marca e quem a endossa via comunicação, ou se o indivíduo for claramente incompatível com as marcas que anuncia. Se a marca for extremamente sofisticada, jovial ou atrativa, e quem a usar não o for, é possível se questionar se a marca ainda assim causaria uma boa impressão em quem a visse.

Em relação à congruência, para Wang e Lin (2011), quando o endossador é congruente com o produto, deverá influenciar positivamente o consumidor, por meio do processo de internalização pelo qual o consumidor pode desenvolver uma atitude favorável em relação ao produto. Os autores questionam se é possível que o endossador da marca não afete todos os observadores, pois nem todos são igualmente atentos a todos os sinais e apelos que as marcas exprimem. Um indivíduo especialista em moda poderá fazer uma avaliação mais apurada, e aquele que valoriza o mercado de luxo pode 
ser mais fortemente influenciado ao observar uma pessoa que usa uma marca de luxo (Das et al., 2010).

Micu, Coulter e Price (2009), em uma pesquisa quantitativa, investigaram o efeito da atratividade em anúncios publicitários e o julgamento que o consumidor faz de si mesmo. O estudo indicou que a atratividade (versus beleza mediana) das modelos favorecia a avaliação do produto, mas gerava baixo julgamento próprio. Entretanto, as mulheres que usavam os produtos anunciados por endossadores atraentes relataram uma avaliação favorável de sua própria atratividade e autoconfiança.

Wang e Lin (2011) estudaram o impacto na intenção de compra, ao manipularem a inserção (ou ausência) de uma celebridade no anúncio publicitário, em conjunto com a relevância das informações sobre o produto. Os resultados indicaram que a inserção do endossador demonstrou efeito significante na avaliação da propaganda e na intenção de compra do produto.

Por fim, em seu estudo, Liu, Huang e Minghua (2007) pesquisaram a relação entre a atratividade do endossador e a congruência com o produto anunciado. Os autores consideraram que as celebridades são eficazes para o endossamento de produtos e que a (alta) congruência entre o endossador e a categoria do produto pode potencializar a atitude positiva em relação ao anúncio/produto.

A revisão teórica demonstrou que a avaliação de marca é potencializada com o uso do endossador figurando no anúncio publicitário, e esse efeito é maior quando o endossante é célebre. Diante disso, propõem-se:

H1a. A propaganda de um produto de uma marca de não luxo será mais bem avaliada quando a estratégia de endossamento for utilizada.

H1b. A propaganda de um produto de marca de não luxo será mais bem avaliada quando o endossamento for realizado por uma celebridade (versus endossante desconhecido).

Contudo, é possível que o fabricante precifique o produto com um valor muito acima de um similar da categoria simplesmente pelas características de distinção, exclusividade e representatividade conferida por uma ML. Sendo assim, é razoável supor que a relação do consumidor com a ML seja ainda mais intensa do que com uma marca de não luxo, o que permite a formulação das seguintes hipóteses: 
H1c. A avaliação da propaganda de um produto de uma ML não sofrerá influência do endossamento realizado por um endossante desconhecido.

H1d. A avaliação da propaganda de um produto de ML não sofrerá influência do endossamento realizado por uma celebridade.

H1e. O efeito das estratégias de endossamento será maior nas propagandas de marcas de não luxo, quando comparado com o efeito nas propagandas das ML.

\section{XPERIMENTO 1}

Conduzimos um experimento com o objetivo de testar a hipótese 1.

\section{Estímulos}

Escolhemos um perfume feminino como produto para figurar na propaganda desse experimento. Para definição das ML e de não luxo, realizamos um brainstorm com a participação de estudantes universitários $(n=6)$ do curso de administração de empresas, que receberam a tarefa de listar marcas de perfumes feminino. Como resultado, foi gerada uma lista contendo 23 marcas de perfumes, que foi submetida a outro grupo de estudantes universitários $(n=30)$, para que avaliassem o grau de luxo percebido da marca, por meio de uma escala de 10 pontos (ancorados em 1 = esta marca não é de luxo e 10 = essa marca é de luxo.

O teste $\mathrm{t}$ de Student para amostras pareadas indicou não haver diferença significante entre as marcas Chanel e Dolce \& Gabbana $\left(\mathrm{M}_{\text {Chanel }}=9,0\right.$ e $\mathrm{M}_{\text {Dolce\&Gabbana }}$ $\left.=8,8 ; \mathrm{t}_{(29)}=0,532 ; \mathrm{p}>5 \%\right)$. Decidimos utilizar a marca Chanel por ter sido considerada com a maior média. Do mesmo modo, utilizamos a marca Avon $(\mathrm{M}=3,1)$ como marca de não luxo, pois foi avaliada com a menor média e também por apresentar diferença significante em relação à marca de luxo que seria utilizada $\left(\mathrm{t}_{(29)}=17,96 ; \mathrm{p}<0,1 \%\right)$.

Para seleção do endossante célebre, solicitamos a seis estudantes universitários do curso de administração de empresas que listassem os nomes de celebridades adequadas para endossar um perfume feminino de uma marca de luxo.

Coletamos fotos das 12 celebridades indicadas. As fotos foram utilizadas em um questionário disponibilizado para que estudantes universitários $(\mathrm{n}=30)$ indicassem o nome da celebridade que estava na foto e, por meio de uma escala de 10 pontos (sendo 1 
$=$ Certamente não e $10=$ Certamente sim), avaliassem se a personalidade da foto poderia ser utilizada em uma propaganda de um perfume feminino de uma marca de luxo.

Apenas oito das 12 celebridades foram reconhecidas, por meio da indicação de seu nome. A celebridade escolhida nesse processo foi Angelina Jolie $(M=8,4)$, pois o teste $\mathrm{t}$ de Student para amostras pareadas indicou haver diferença significante entre avaliação de adequação do endossante em relação ao segundo mais bem avaliado $\left(\mathrm{M}_{\text {Gisele Bündchen }}=7,0 ; \mathrm{t}_{(29)}=2,23 ; \mathrm{p}<5 \%\right)$.

Finalmente, para definição do endossante não célebre, coletamos da web sete fotos de modelos que não estavam participando de campanhas publicitárias e as utilizamos em um questionário, para que 30 estudantes universitários do curso de administração de empresas indicassem as três mais adequadas para participar de uma propaganda de um perfume feminino de uma marca de luxo, em ordem de preferência (do $1^{\circ}$ ao $3^{\circ}$ lugar). Solicitamos também que indicassem se conheciam a modelo, por meio de uma escala de 10 pontos (sendo $1=$ certamente desconheço e $10=$ certamente conheço). A modelo escolhida teve $36,67 \%$ das indicações como a preferida ( $1^{\circ}$ lugar, $n$ $=11)$ e $30 \%$ como a segunda escolha $\left(2^{\circ}\right.$ lugar, $\left.n=9\right)$. Além disso, os respondentes indicaram que a modelo possui baixo grau de notoriedade $\left(\mathrm{M}_{\text {reconhecimento }}=1,8\right)$.

\section{Desenho experimental e medidas}

Definidos os estímulos que seriam utilizados, desenvolvemos propagandas em desenho fatorial completo entre sujeitos no formato $3 \times 2$, sendo 3 estratégias de endossamento (célebre, não célebre e sem endosso) versus 2 marcas (luxo e não luxo).

O formulário de coleta de dados final continha, além das propagandas, quatro questões para verificação da eficiência da manipulação (manipulation checks), solicitando que os respondentes indicassem, por meio de uma escala do tipo Likert de cinco pontos (variando entre $1=$ Discordo totalmente e 5 = Concordo totalmente), o reconhecimento da marca (Certamente eu conheço esta marca de perfume), o grau de luxo percebido da marca (A marca de perfume desta propaganda é de luxo), o quanto reconheciam a personalidade que estava endossando a propaganda do perfume (Certamente eu conheço a modelo apresentada na propaganda do perfume) e o quanto o endossador era adequado para fazer uma campanha publicitária daquela marca de 
perfume (Certamente esta modelo é adequada para fazer uma propaganda de um perfume feminino desta marca).

A variável dependente (Avaliação) foi mensurada por meio de cinco itens (Esta marca de perfume é ótima; Certamente compraria esta marca de perfume; Eu recomendaria esta marca de perfume a um amigo; Esta marca de perfume atende às minhas necessidades; Eu confio nesta marca de perfume), adaptados de Lopes, Silva e Hernandez (2013), por meio de uma escala do tipo Likert de cinco pontos (variando entre $1=$ Discordo totalmente e $5=$ Concordo totalmente).

Para análise dos dados, utilizamos a análise de variância univariada (Anova) por meio do SPSS 18.0.

\section{Amostra e procedimentos de campo}

A amostra deste experimento (assim como a amostra do Experimento 2) foi constituída por alunos universitários de nove cursos (Comércio Exterior, Administração, Marketing, Ciências Contábeis, Nutrição, Gestão da Qualidade, Logística, Processos Gerenciais e Economia) de dois grandes centros universitários do estado de São Paulo.

Para evitarmos vieses, os questionários foram distribuídos seguindo o procedimento denominado por Kardes (2002), com randomização completa entre sujeitos. Os questionários formam misturados aleatoriamente, possibilitando que qualquer um de seus seis modelos fosse respondido por qualquer estudante. Mesmo com a tomada desses cuidados, a amostra deve ser classificada como não probabilística por conveniência (Malhotra, 2005).

\section{Resultados do Experimento 1}

A amostra do Experimento 1 foi composta por 302 estudantes, sendo $188(62,2 \%)$ do sexo feminino, com idade média de 25 anos $(\mathrm{s}=6,27)$. Dentre os respondentes, $52 \%$ $(n=157)$ estudavam no período diurno ou vespertino e $90 \%(n=271)$ exerciam também alguma atividade remunerada $(72,1 \%, \mathrm{n}=218$, com salários até $\mathrm{R} \$$ $2.000,00 /$ mensais).

A avaliação dos estímulos foi equilibrada, pois 155 estudantes avaliaram as propagandas da marca de luxo, enquanto outros 147 avaliaram as propagandas da marca 
de não luxo. $\mathrm{O}$ mesmo equilíbrio foi obtido na avaliação dos estímulos de celebridade, conforme demonstrado na Figura 1.

Figura1 - Distribuição das avaliações das propagandas do Experimento 1.

\begin{tabular}{|l|l|l|l|l|l|l|}
\hline Endosso & \multicolumn{2}{|l|}{ Marca de Luxo } & \multicolumn{2}{l|}{ Marca de não luxo } & \multicolumn{2}{l|}{ Total } \\
\hline & $\mathrm{n}$ & $\%$ & $\mathrm{~N}$ & $\%$ & $\mathrm{~N}$ & $\%$ \\
\hline Celebridade & 46 & $29,7 \%$ & 38 & $25,9 \%$ & 84 & $27,8 \%$ \\
\hline Não célebre & 54 & $34,8 \%$ & 54 & $36,7 \%$ & 108 & $35,8 \%$ \\
\hline Sem endosso & 55 & $35,5 \%$ & 55 & $37,4 \%$ & 110 & $36,4 \%$ \\
\hline Total & 155 & $100,0 \%$ & 147 & $100,0 \%$ & 302 & $100,0 \%$ \\
\hline
\end{tabular}

Fonte: Resultados da pesquisa

As manipulations check indicaram que a manipulação dos estímulos foi adequada. Houve diferença significante entre o reconhecimento do endossante célebre $(M=4,4)$ e do endossante não célebre $\left(\mathrm{M}=1,6 ; \mathrm{t}_{(187)}=15,43 ; \mathrm{p}<1 \%\right)$, porém, como se esperava, não houve diferença significante em relação à adequação do endossante para a propaganda $\left(\mathrm{M}_{\text {célebre }}=3,9\right.$ e $\left.\mathrm{M}_{\text {não célebre }}=3,8, \mathrm{t}_{(187)}{ }^{=} 0,74 ; \mathrm{p}>10 \%\right)$.

Do mesmo modo, o luxo percebido da marca de luxo foi estatisticamente maior que o luxo percebido da marca de não luxo $\left(\mathrm{M}_{\text {luxo }}=4,4\right.$ e $\mathrm{M}_{\text {não luxo }}=2,2, \mathrm{t}_{(297)}=17,80$; $\mathrm{p}<1 \%$ ). Também como se desejava, não houve diferença significante do reconhecimento das marcas envolvidas no experimento $\left(\mathrm{M}_{\text {luxo }}=4,4\right.$ e $\mathrm{M}_{\text {não luxo }}=4,3$, $\left.\mathrm{t}_{(296)}=0,11 ; \mathrm{p}>10 \%\right)$.

Para a variável dependente, utilizamos o score agregado dos cinco itens de avaliação (Alpha de Cronbach = 0,83).

Como esperávamos, a Anova identificou efeito principal para a Marca $\left(\mathrm{F}_{(1,296)}=\right.$ $25,62 ; \mathrm{p}<1 \%)$, mas não identificou efeito principal para o Endosso $\left(\mathrm{F}_{(2,296)}=3,74\right.$; p $>10 \%)$. Também não foi identificado efeito de interação entre Marca e Endosso $\left(\mathrm{F}_{(2,296)}=1,73 ; \mathrm{p}>10 \%\right)$.

Não houve diferença significativa na avaliação da marca de luxo em qualquer cenário de endossamento $\left(\mathrm{M}_{\text {endosso célebre }}=3,44, \mathrm{M}_{\text {endosso não célebre }}=3,43\right.$ e $\mathrm{M}_{\text {sem endosso }}=$ 3,43). Porém, houve diferença na avaliação da marca de não luxo endossada por uma celebridade $(\mathrm{M}=3,1)$, quando comparada com o endossamento realizado por um endossante não célebre $\left(\mathrm{M}=2,8, \mathrm{t}_{(90)}=2,653 ; \mathrm{p}<5 \%\right)$.

Do mesmo modo, verificamos que existe diferença significativa entre a avaliação de marca de não luxo endossada por celebridade e a mesma marca sem endosso $(\mathrm{M}=$ 
$\left.2,5, \mathrm{t}_{(91)}=2,92 ; \mathrm{p}<1 \%\right)$. Todavia, não verificamos diferença entre a avaliação da marca de não luxo endossada por não célebre versus sem endossamento $\left(\mathrm{M}_{\text {endosso não célebre }}=2,8\right.$, $\left.\mathrm{M}_{\text {sem endosso }}=2,5, \mathrm{t}(107)=1,16 ; \mathrm{p}>10 \%\right)$.

A última análise realizada indicou que a avaliação da marca de não luxo foi positivamente potencializada pelo endosso da celebridade, aproximando-a da avaliação realizada para a marca de luxo $\left(\mathrm{M}_{\text {luxo }}=3,4, \mathrm{M}_{\text {não luxo }}=3,1, \mathrm{t}_{(82)}=1,37 ; \mathrm{p}>10 \%\right)$.

A Figura 2 representa graficamente os resultados obtidos na Anova.

Figura 2 - Médias identificadas na análise de variância.

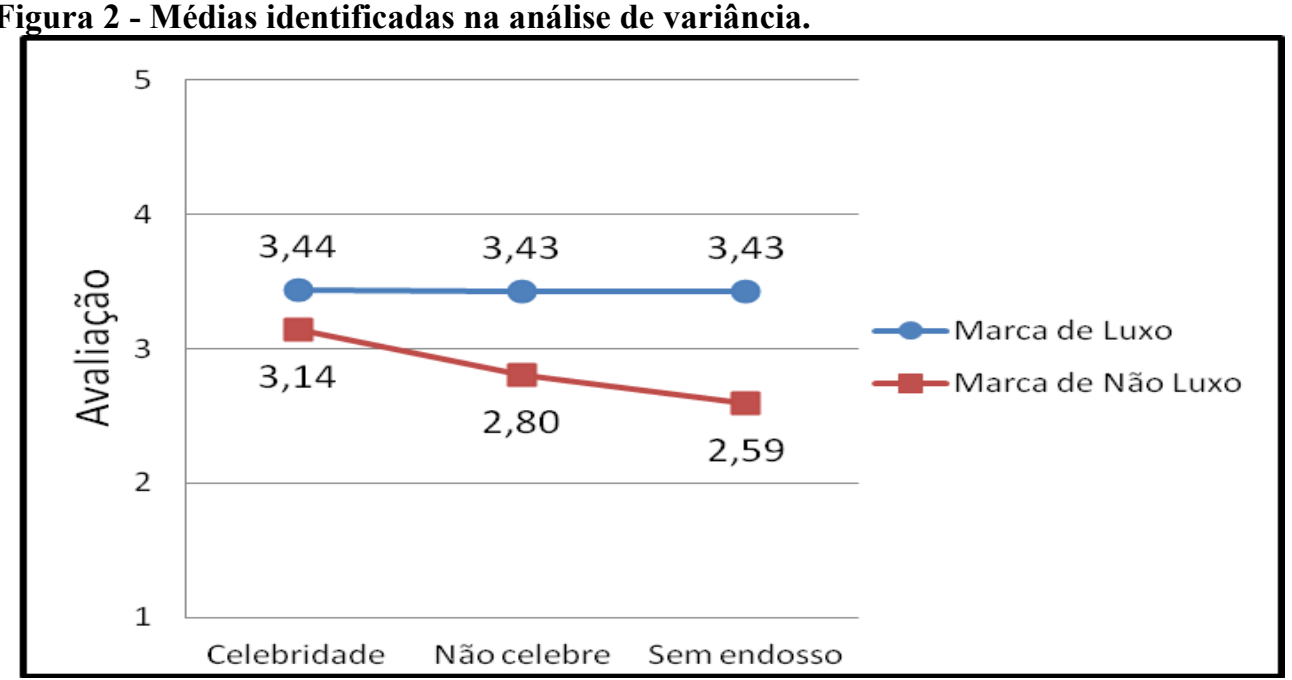

Fonte: Resultados da pesquisa

\section{Discussão dos resultados do Experimento 1}

Os resultados indicam que uma marca de luxo não é favorecida pelo endossamento de uma celebridade, diferentemente do que acontece com a avaliação da marca de não luxo. Assim sendo, identificou-se o fenômeno já preconizado por Kapferer.

Aparentemente, os indivíduos ancoram sua avaliação da marca de luxo exclusivamente na marca, não importando a estratégia de endossamento adotada por um anunciante.

Por outro lado, a avaliação uma marca de não luxo é favorecida tanto pelo endossamento de um não célebre congruente com a categoria de produtos tanto quanto, e ainda mais, por uma celebridade.

Há indícios de que uma celebridade com alta congruência com a categoria do produto anunciado favoreça uma marca de não luxo, porém reconhecida, tornando sua avaliação tão positiva quanto uma marca de luxo. 


\section{O EFEITO PAÍS E ORIGEM}

O efeito país de origem é resultante dos estereótipos que as pessoas tendem a desenvolver com relação a países e, consequentemente, em relação aos produtos neles fabricados, que poderão determinar a avaliação de marcas, intenção de compra e comportamento (Giraldi, 2006; Meirelles, Strehlau \& Lopes, 2016).

A informação sobre o país onde o produto foi fabricado tem um efeito cognitivo que pode interferir na imagem que o consumidor tem do produto (Sohail, 2005; Chyssochoidis, Krystallis \& Perreas, 2007; Fetscherin \& Toncar, 2009).

Frequentemente, o consumidor constrói estereótipos a respeito de um país, o que afetará a imagem dos produtos ali produzidos (Yu, Park, \& Cho, 2007). Estudos anteriores demonstraram variações desse fenômeno entre países e categorias de produtos (Sohail, 2005; Yu, Park, \& Cho, 2007; Aiello et al., 2009; Fetscherin \& Toncar, 2009), sendo que alguns demonstram que os produtos produzidos em países desenvolvidos são mais bem avaliados do que os produzidos em países subdesenvolvidos (Yassin, Noor e Mohamad, 2007; Fetscherin \& Toncar, 2009; Meirelles, Strehlau \& Lopes, 2016).

Quando os consumidores não estão familiarizados com determinados produtos, usarão o fator imagem do país de origem como um critério de avaliação. Marcas oriundas de países com imagens positivas deverão ser mais facilmente aceitas, em comparação àquelas cuja imagem do país de origem é negativa, sendo que essa correlação também é frequentemente observada em relação à lealdade às marcas (Yassin, Noor e Mohamad, 2007; Aiello et al., 2009).

Yassin, Noor e Mohamad (2007) sugerem que os consumidores farão suas escolhas baseados na informação do "made in" constantes na embalagem e avaliarão o produto como superior ou inferior, de acordo com as percepções que têm a respeito daquele país. Já Chryssochoidis, Krystallis e Perreas (2007) afirmam que os estudos internacionais envolvendo o efeito país de origem na avaliação de vários produtos por consumidores revelaram resultados diversos e até contraditórios, possivelmente devido às diferentes combinações de amostra, país e produto estudados. A maioria dos estudos, segundo os autores, enfatiza a multidimensionalidade do efeito país de origem. A informação contida na embalagem a respeito de onde o produto foi fabricado tem 
influência na percepção do consumidor em relação à qualidade. Entretanto, a magnitude desse efeito depende da categoria e também de atributos específicos do produto.

Giraldi (2006) apresenta o estudo de Verlegh e Steenkamp (1999), no qual foi realizada uma meta-análise relativa a 41 estudos anteriores sobre o efeito país de origem, conduzidos entre 1980 e 1986. Dentre as várias constatações obtidas por meio da meta-análise, ressaltam-se três, em especial: a) não foram encontradas diferenças significativas entre o efeito para produtos híbridos (projetados em um país e fabricados em outro) e não híbridos; b) os estudos com desenho experimental do tipo betweensubjects, nos quais os participantes se posicionam a respeito de um produto somente, levam a influências menores de efeito país de origem do que estudos do tipo withinsubject, nos quais os mesmos respondentes fornecem avaliações sobre vários produtos, e; c) o impacto do efeito país de origem não difere entre estudos que utilizam amostras de estudantes e estudos que utilizam amostras de consumidores em geral.

$\mathrm{O}$ efeito país de origem relaciona-se com o estereótipo que as pessoas constroem a respeito de uma localidade que, ao longo do tempo, desenvolveu uma boa (ou má) reputação de produção de determinados produtos. Dessa forma, a tendência é que o consumidor generalize, associando boa (ou má) qualidade quando a procedência do produto estiver disponível no conjunto de informações avaliadas. Relacionando os conceitos de marca de luxo e efeito país, são formuladas as seguintes hipóteses:

H2a. A percepção estereotipada negativa (versus positiva) do consumidor em relação a um país influenciará negativamente (versus positivamente) a avaliação de uma ML oriunda daquele país.

H2b. A percepção estereotipada negativa (versus positiva) do consumidor em relação a um país influenciará negativamente (versus positivamente) a avaliação de uma marca de não luxo oriunda daquele país.

H2c. O efeito país negativo será maior nas marcas de não luxo (versus marcas de luxo).

\section{EXPERIMENTO 2}

Um segundo experimento foi conduzido para testar a hipótese 2. 


\section{Estímulos}

Escolhemos um relógio de pulso masculino como produto, para figurar na propaganda deste experimento. Para definição das ML e de não luxo, realizamos um brainstorm com a participação de estudantes universitários $(\mathrm{n}=6)$ do curso de administração de empresas, que receberam a tarefa de listar marcas de relógios de pulso masculinos.

Como resultado, foi gerada uma lista contendo 14 marcas de relógio, que foi submetida a outro grupo de estudantes universitários $(\mathrm{n}=30)$, para que avaliassem o grau de luxo percebido da marca, por meio de uma escala de 10 pontos (ancorados em 1 = esta marca não é de luxo e $10=$ esta marca é de luxo. O teste t de Student para amostras pareadas indicou haver diferença entre o luxo percebido da marca de maior média $\left(M_{\text {Rolex }}=9,7\right)$ e a segunda mais bem avaliada $\left(\left(M_{\text {Ferrari }}=8,56 ; t_{(29)}=2,984\right.\right.$; $\mathrm{p}<1 \%$ ). Observamos também que a avaliação da marca com maior média (Rolex) foi muito superior à avaliação da marca de menor média $\left(M_{\text {Orient }}=4,6, \mathrm{t}_{(29)}=10,45 ; \mathrm{p}<1 \%\right.$ ). Com esse resultado, utilizamos a marca Rolex como de luxo e a marca Orient como de não luxo.

Para seleção do estímulo país de origem, solicitamos que seis estudantes universitários indicassem nomes de países que suscitassem alta qualidade percebida na manufatura de relógios de pulso e, a outros seis, que indicassem países que suscitassem baixa qualidade de manufatura do mesmo produto. Compilamos as duas listas em um único formulário e pedimos que outro grupo de estudantes universitários ${ }^{\mathrm{i}}(\mathrm{n}=30)$ avaliasse os nomes dos países, utilizando uma escala de 10 pontos $(1=$ A qualidade dos relógios fabricados neste país é péssima e $10=$ A qualidade dos relógios fabricados neste país é ótima).

O país selecionado como de alta qualidade de manufatura de relógios foi a Suíça $(\mathrm{M}=9,0)$, pois o teste t para amostras pareadas indicou haver diferença significativa entre sua avaliação de qualidade manufatureira, em relação ao segundo mais bem avaliado $\left(\mathrm{M}_{\text {Itália }}=8,6 ; \mathrm{t}_{(29)}=1,293 ; \mathrm{p}<1 \%\right)$. Por outro lado, o país com menor média em qualidade de manufatura foi Moçambique $(\mathrm{M}=3,1)$, seguido da África do Sul $(\mathrm{M}=$ $3,3)$ e Paraguai $(M=3,6)$. O teste $t$ para amostras pareadas indicou haver diferença significativa entre a avaliação de Moçambique $(M=3,1)$ e África do Sul $\left(M=3,3 ; t_{(29)}\right.$ $=0,745 ; \mathrm{p}<0,05)$. 
Com isto, definimos os estímulos de ML (Rolex) e de não luxo (Orient) e os países para efeito negativo (Moçambique) e positivo (Suíça).

\section{Desenho experimental e medidas}

Definidos os estímulos que seriam utilizados, desenvolvemos propagandas em desenho fatorial completo entre sujeitos no formato $3 \times 2$, sendo 3 países de origem (estereótipo de alta qualidade, estereótipo de baixa qualidade e sem país de origem) versus 2 marcas (luxo e não luxo).

O formulário de coleta de dados final continha, além das propagandas, três questões para verificação da eficiência da manipulação (manipulation checks), solicitando que os respondentes indicassem, por meio de uma escala do tipo Likert de 5 pontos (variando entre $1=$ Discordo totalmente e 5 = Concordo totalmente), o reconhecimento da marca (Certamente eu conheço esta marca de relógio), o grau de luxo percebido da marca (A marca de relógio desta propaganda é de luxo), e a qualidade manufatureira do país que figurava na condição de "made in" da propaganda (O país de origem da fabricação deste relógio transmite imagem de alta qualidade na fabricação de relógios).

A variável dependente (Avaliação) foi mensurada por meio de cinco itens (Esta marca de relógios é ótima; Certamente compraria esta marca de relógios; Eu recomendaria esta marca de relógios a um amigo; Esta marca de relógios atende às minhas necessidades; Eu confio nesta marca de relógios), adaptados de Lopes, Silva e Hernandez (2013), por meio de uma escala do tipo Likert de 5 pontos (variando entre 1 $=$ Discordo totalmente e $5=$ Concordo totalmente).

Para análise dos dados, utilizamos a análise de variância univariada (Anova), por meio do SPSS 18.0.

\section{Resultados do Experimento 2}

A amostra do Experimento 2 foi composta por 329 estudantes, sendo 185 (56,2\%) do sexo feminino, com idade média de 24 anos $(\mathrm{s}=6,79)$. Dentre os respondentes, $62 \%$ $(\mathrm{n}=204)$ estudavam no período diurno ou vespertino e 91,1\% $(\mathrm{n}=300)$ exerciam também alguma atividade remunerada $(70,8 \%, \mathrm{n}=233$, com salários até $\mathrm{R} \$$ $2.000,00 /$ mensais). 
A avaliação dos estímulos foi equilibrada, pois 165 estudantes avaliaram as propagandas da marca de luxo, enquanto outros 164 avaliaram as propagandas da marca de não luxo. O mesmo equilíbrio foi obtido na avaliação dos estímulos de celebridade, conforme demonstrado na Figura 3.

Figura 3 - Distribuição das avaliações das propagandas do Experimento 2

\begin{tabular}{|l|c|c|c|c|c|c|}
\hline País de origem & \multicolumn{2}{l|}{ Luxo } & \multicolumn{2}{l|}{ Não luxo } & \multicolumn{2}{l|}{ Total } \\
\hline & $\mathrm{n}$ & $\%$ & $\mathrm{n}$ & $\%$ & $\mathrm{n}$ & $\%$ \\
\hline Estereótipo de alta qualidade & 55 & $33,3 \%$ & 55 & $33,5 \%$ & 110 & $33,4 \%$ \\
\hline Estereótipo de baixa qualidade & 56 & $33,9 \%$ & 55 & $33,5 \%$ & 111 & $33,7 \%$ \\
\hline Sem país de origem & 54 & $32,7 \%$ & 54 & $32,9 \%$ & 108 & $32,8 \%$ \\
\hline Total & 165 & $100,0 \%$ & 164 & $100,0 \%$ & 329 & $100,0 \%$ \\
\hline
\end{tabular}

Fonte: Resultados da pesquisa

A análise dos resultados indicou que a manipulação dos estímulos foi adequada. Houve diferença significativa entre o luxo percebido entre a marca de luxo $\left(\mathrm{M}_{\text {Rolex }}=\right.$ 4,5 ) e a marca de não luxo (Morient $=3,47, \mathrm{t}_{(328)}=9,60 ; \mathrm{p}<5 \%$ ); porém, como se esperava, não houve diferença significante em relação ao reconhecimento das marcas

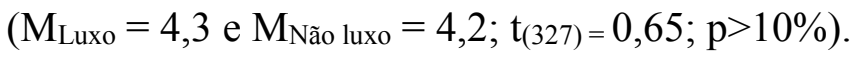

Do mesmo modo, a qualidade percebida para manufatura de relógios foi estatisticamente diferente entre os países utilizados $\left(\mathrm{M}_{\text {Moçambique }}=3,0\right.$ e $\mathrm{M}_{\text {Suíça }}=4,2$, $\left.\mathrm{t}_{(219)}=7,50 ; \mathrm{p}<5 \%\right)$.

Para a variável dependente, utilizamos o score agregado dos cinco itens de avaliação (Alpha de Cronbach $=0,79)$.

A Anova identificou efeito principal para a marca $\left(\mathrm{F}_{(1,323)}=36,17 ; \mathrm{p}<1 \%\right)$ e efeito principal para o país de origem $\left(\mathrm{F}_{(1,323)}=5,49 ; \mathrm{p}<1 \%\right)$. Contudo, não foi identificado efeito de interação entre marca e país de origem $\left(\mathrm{F}_{(2,323)}=0,63 ; \mathrm{p}>10 \%\right)$.

Nas avaliações da ML, não houve diferença significativa em qualquer cenário de país de origem, independentemente da qualidade percebida $\left(\mathrm{M}_{\text {Suíça }}=3,7, \mathrm{M}_{\text {Moçambique }}=\right.$ $3,4\left[\mathrm{t}_{(109)}=2,11 ; \mathrm{p}>5 \%\right]$ e $\left.\mathrm{M}_{\text {Sem país }}=3,7\left[\mathrm{t}_{(107)}=0,52 ; \mathrm{p}>10 \%\right]\right)$. Mesmo que a avaliação da marca tenha sido menos positiva quando um país de origem de baixa qualidade percebida foi utilizado, a diferença identificada não foi significativa.

Por outro lado, a avaliação da marca de não luxo foi mais positiva, quando um país de origem de alta qualidade percebida era considerado $\left(\mathrm{M}_{\text {Alta }}\right.$ qualidade $=3,2, \mathrm{M}_{\text {Baixa }}$ qualidade $\left.=2,7, \mathrm{t}_{(107)}=3,04 ; \mathrm{p}<5 \%\right)$. 
Verificamos também que a ausência do país de origem não melhora significativamente a avaliação da marca, quando se compara com o cenário de país de baixa qualidade percebida $\left(\mathrm{M}_{\text {Baixa qualidade }}=2,7, \mathrm{M}_{\text {Sem país de origem }}=2,9, \mathrm{t}_{(107)}=1,02\right.$; $\mathrm{p}>10 \%$.

Testes post hoc indicaram ainda que a marca de luxo é mais bem avaliada que a marca de não luxo em qualquer cenário em que isto ocorra (todos com diferença significativa a $1 \%)$.

A Figura 4 apresenta graficamente as médias obtidas no Experimento 2.

Figura 4 - Médias identificadas na análise de variância

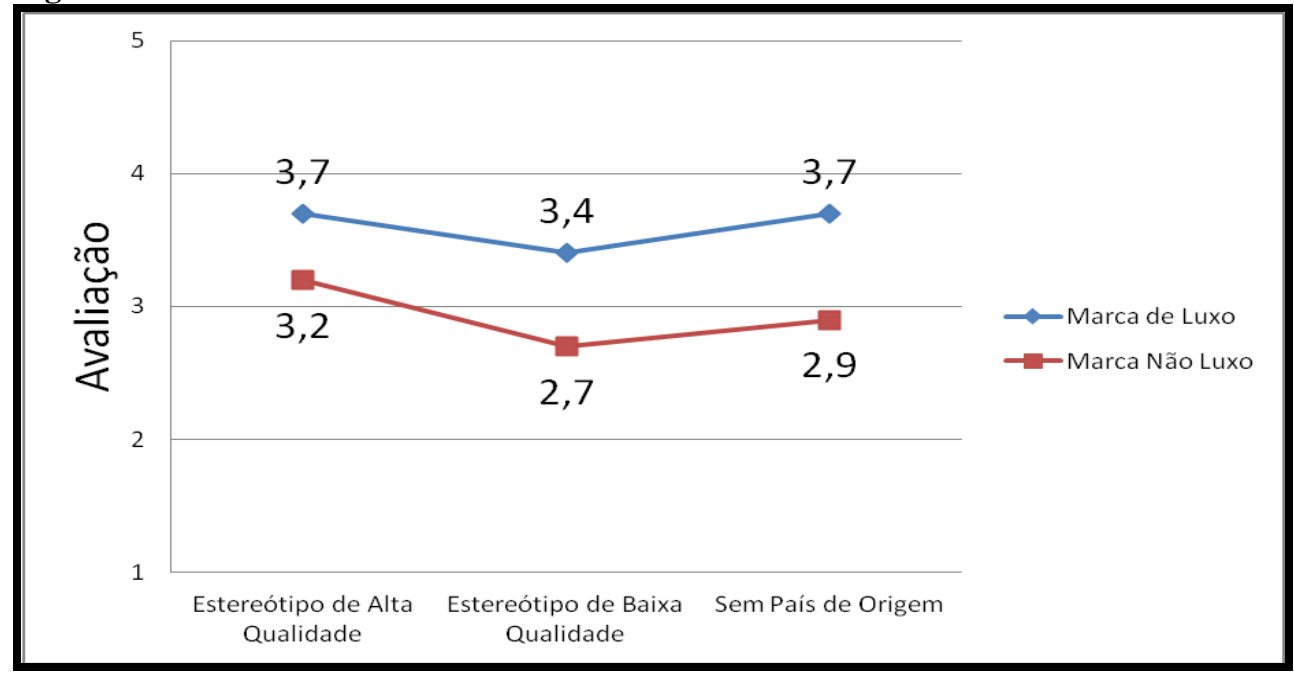

Fonte: Resultados da pesquisa

\section{Discussão dos resultados do Experimento 2}

Os resultados indicaram que o efeito país de origem é mais forte quando uma marca de não luxo está sendo avaliada. Nesse contexto, não foi identificada diferença entre o efeito país de origem negativo e a omissão da informação do país de manufatura.

Por outro lado, foram encontrados indícios de que uma marca de luxo pode ter sua avaliação deteriorada quando for associada a um país de origem de baixa qualidade percebida, mesmo que esse efeito não tenha sido significativo neste estudo.

Diferentemente do que era esperado, uma ML não é beneficiada pelo efeito país de origem positivo. Este fenômeno é verificado somente na avaliação das marcas de não luxo. Por outro lado, o efeito país de origem negativo não afetou significativamente a avaliação da marca de luxo. 
O efeito país de origem foi mais intenso nas avaliações da marca de não luxo, o que está coerente com os achados de Aiello et al. (2009), que preconizou que as marcas de luxo são mais importantes do que a sua origem.

\section{DISCUSSÃO DOS RESULTADOS EMPÍRICOS DO ESTUDO}

Os resultados levam à dedução de que o endosso não traz diferenças significativas para a marca de luxo, independentemente de o anúncio apoiar-se no endosso de uma celebridade ou na utilização de um modelo não célebre. Dessa forma, a propaganda de um produto de uma ML não será mais bem avaliada quando utilizada a estratégia de endossamento, nem mesmo quando este é feito por uma celebridade.

Por outro lado, os resultados apontam que a propaganda de um produto de uma marca de não luxo será mais bem avaliada quando a estratégia de endossamento for utilizada por endossador célebre ou não célebre.

Liu, Huang e Minghua (2007) explicam que os endossadores podem ser persuasivos ao consumidor, porém de maneiras diferentes, dependendo do tipo de produto e do grau de envolvimento do consumidor. No caso das ML, pode-se inferir que, possivelmente, o vínculo do consumidor com a própria marca é mais forte que o papel que o endossador possa representar no processo de comunicação pela mensagem transmitida no anúncio publicitário.

Já o posicionamento de Carroll (2009), de que o uso de celebridades como endossadores da marca produz impacto maior quando comparado ao dos anúncios que utilizam endossadores não célebres, mostrou-se vulnerável quando uma ML está sendo avaliada. Esse fato pode ser justificado pelo argumento de Das et al. (2010), que entendem que as ML podem representar mais do que as tradicionalmente esperadas qualidade e confiabilidade.

O segundo experimento, voltado para a avaliação do efeito país de origem na percepção de qualidade do produto em anúncios publicitários, investigou tal fenômeno na avaliação de ML e de não luxo. Neste experimento, identificamos que a percepção estereotipada positiva do consumidor em relação a um país não deverá influenciar positivamente a avaliação de uma marca de luxo oriunda daquele país. Os resultados da marca de luxo com efeito país de origem positivo e sem efeito país de origem são próximas para essa categoria de marca, que se sustenta na mente do consumidor, 
independentemente da associação ou não com a imagem de qualidade do país de origem.

Também é possível deduzir que percepção estereotipada negativa do consumidor em relação a um determinado país poderá influenciar negativamente a avaliação de uma marca de luxo oriunda daquele país. Mesmo que esse efeito não tenha sido significante, há indícios de que isso possa acontecer. Também se pode inferir que a percepção estereotipada negativa do consumidor em relação a um país deverá influenciar negativamente a avaliação de uma marca de não luxo oriunda daquele país, pois a média de avaliação é menor, quando inserido no anúncio publicitário o efeito país de origem negativo.

Os resultados levam à confirmação de que o efeito país de origem, definido por Giraldi (2006) como os estereótipos que as pessoas tendem a desenvolver com relação a países e, consequentemente, em relação aos produtos neles fabricados, poderá influenciar a avaliação de marcas, tanto para ML quanto para marcas de não luxo. A afirmação da autora é apoiada também por Fetscherin e Toncar (2009) e por Aiello et al. (2009).

\section{CONSIDERAÇÕES FINAIS}

O objetivo principal deste estudo foi verificar o efeito do endossamento por celebridades e o efeito país de origem na avaliação de ML. Para tanto, conduzimos dois experimentos, que testaram as hipóteses formuladas com base na teoria sobre a temática. Na Figura 5, indica-se o resultado do teste das hipóteses. 
Figura 5 - Resultado do teste das hipóteses.

\begin{tabular}{|c|c|c|}
\hline \multicolumn{2}{|c|}{ Hipóteses } & \multirow{2}{*}{$\begin{array}{l}\text { Resultado } \\
\text { Não rejeitada }\end{array}$} \\
\hline H1a & $\begin{array}{l}\text { A propaganda de um produto de uma marca de não luxo será mais bem avaliada } \\
\text { quando a estratégia de endossamento for utilizada. }\end{array}$ & \\
\hline $\mathrm{H} 1 \mathrm{~b}$ & $\begin{array}{l}\text { A propaganda de um produto de marca de não luxo será mais bem avaliada } \\
\text { quando o endossamento for realizado por uma celebridade (versus endossante } \\
\text { desconhecido). }\end{array}$ & Não rejeitada \\
\hline $\mathrm{H} 1 \mathrm{c}$ & $\begin{array}{l}\text { A avaliação da propaganda de um produto de uma marca de luxo não sofrerá } \\
\text { influência do endossamento realizado por um endossante desconhecido. }\end{array}$ & Não rejeitada \\
\hline H1d & $\begin{array}{l}\text { A avaliação da propaganda de um produto de marca de luxo não sofrerá } \\
\text { influência do endossamento realizado por uma celebridade. }\end{array}$ & Não rejeitada \\
\hline H1e & $\begin{array}{l}\text { O efeito das estratégias de endossamento será maior nas propagandas de marcas } \\
\text { de não luxo quando comparado com o efeito nas propagandas das marcas de } \\
\text { luxo. }\end{array}$ & Não rejeitada \\
\hline $\mathrm{H} 2 \mathrm{a}$ & $\begin{array}{l}\text { A percepção estereotipada negativa (versus positiva) do consumidor em relação } \\
\text { a um país influenciará negativamente (versus positivamente) a avaliação de uma } \\
\text { marca de luxo oriunda daquele país. }\end{array}$ & Rejeitada \\
\hline $\mathrm{H} 2 \mathrm{~b}$ & $\begin{array}{l}\text { A percepção estereotipada negativa (versus positiva) do consumidor em relação } \\
\text { a um país influenciará negativamente (versus positivamente) a avaliação de uma } \\
\text { marca de não luxo oriunda daquele país. }\end{array}$ & Não rejeitada \\
\hline $\mathrm{H} 2 \mathrm{c}$ & $\begin{array}{l}\text { O efeito país negativo será maior nas marcas de não luxo (versus marcas de } \\
\text { luxo). }\end{array}$ & Não rejeitada \\
\hline
\end{tabular}

Fonte: os autores

Uma das contribuições gerenciais deste estudo foi demonstrar que existem diferenças no resultado da gestão de marketing de luxo em relação ao marketing de massa. A figura de um endossador tem efeito na percepção positiva da avaliação de uma marca de não luxo. Para a ML, essa estratégia de comunicação não tem o mesmo efeito, dado que a própria marca é o vetor que propulsiona a demanda. Assim, reforça-se que gestores de marcas de não luxo podem utilizar endossadores como componente das estratégias de divulgação da marca.

As ML que utilizam celebridades para endossar seus produtos estão atuando fora da estratégia do luxo e operando uma estratégia de marketing mais aplicada ao mercado de grandes volumes de produção. Como contribuição aos gestores, é recomendável que se mensure o investimento em celebridades para endossar suas marcas de luxo. Pode ser que o alto investimento realizado para contratação de uma celebridade não se justifique, pois os anúncios publicitários teriam o mesmo efeito sem sua presença. 
Em relação ao efeito país de origem, percebe-se que, sem sua identificação, a avaliação da ML é, como se esperava, superior à avaliação da marca de não luxo.

No caso de ML, a identificação do país com imagem de alta qualidade praticamente remete a percepção do consumidor aos mesmos níveis que teriam sem a indicação do país de origem. Portanto, associação da marca a um país de origem com alta qualidade tem mais efeito para produtos de não luxo. Contudo, as marcas continuam sendo o vetor da demanda para produtos de luxo.

Do ponto de vista acadêmico, o estudo permitiu analisar o uso do endosso com celebridade e com endossador não célebre em anúncios publicitários de ML. Avaliou também o efeito país de origem para esse tipo de marca. Dessa forma, esta pesquisa vinculou a temática específica do mercado de luxo à área da comunicação publicitária, enfocando duas variáveis experimentais que influenciam na percepção do público-alvo de anúncios de marcas de luxo e de não luxo.

Ainda sobre a contribuição teórica deste trabalho, levantou-se o questionamento sobre a aplicação das teorias de marca nos efeitos que envolvem as marcas de luxo. É possível compreender, então, que este estudo contribuiu para a teoria, na medida em que demonstra que pressupostos da teoria das marcas não foram confirmados para as marcas de luxo. Portanto, esse é um ponto divergente a ser explorado futuramente por novos estudos. Além disso, conforme apontaram Aiello et al. (2009), as pessoas jovens tendem a ter mais interesse em marcas e na sua nacionalidade. Sendo assim, outra sugestão de estudos futuros relaciona-se a compreender as diferenças com base na idade dos respondentes.

\section{REFERÊNCIAS}

Aiello, G.; Donvito, R.; Godey, B.; Pederzoli, D.; Wiedmann, K.-P.; Hennigs, N. \& Singh, R. (2009). An international perspective on luxury brand and country-of-origin effect. Journal of Brand Management, 16 (5/6), 323-337.

Aiello, Gaetano; Donvito, Rafaelle; Godey, Bruno; Pederzoli, Daniele \& Wiedmann, Allérès, Danielle (2006) Luxo... estratégias, marketing. São Paulo: FGV.

Atwal G. \& Williams, A. (2009). Luxury brand marketing - the experience is everything! The Journal of Brand Management, vol. 16 issue 5.

Bastien, V. \& Kapferer, J.-N. (2013). More on Luxury anti-laws of Marketing. In: K.-P. Wiedmann, \& N. Hennigs (Eds.), Luxury marketing: A challenge for theory and practice (pp. 19-34). Wiesbaden: Springer Gabler. 
Bellaiche, J. M.; Mei-Pochtler, A. \& Hanisch, D. (2010). The new world of luxury: cough between growing momentum and lasting change. The Boston Consulting Group.

Carroll, Angela (2009). Brand communications in fashion categories using celebrity endorsement. Journal of Brand Management. Vol. 17.

Castarède, J. (2005). O Luxo: O segredo dos produtos mais desejados do mundo. São Paulo: Barcarolla.

Christodoulides, George; Michaelidou, Nina \& Li, Ching Hsing (2009). Measuring perceived brand luxury: An evaluation of the BLI scale. Journal of Brand Management. Vol. 16, 5/6, pp. 395-405.

Chyssochoidis, George \& Krystallis, Athanassios (2007). Ethicentric beliefs and country of origin (COO) effect: impact of country, product and product attributes on Greek consumer's evaluation of food products. European Journal of Marketing. Vol. 41. No. $11 / 12$.

Das, Enny; Vermeulen, Ivar; Laagland, Tessa \& Postma, Almer (2010). When you are what you own: do physically attractive people benefit more from owning sophisticated brands? International Journal of Advertising.

De Toni, D., Bacichetto, V. D. V., Milan, G. S., \& Larentis, F. (2014). A Relação entre Conhecimento da Marca e Nível de Preço na Intenção de Compra: Um Experimento com Perfumes de Luxo. REMark, vol. 13, n.3, pp.108-122.

Dubois, Bernard \& Paternault, Claire ( jul./ago.1995). Observations: understanding the world of international luxury brands: the "dream formula". Journal of Advertising Research.

Fetscherin, Marc \& Toncar, Mark (2009). Country of origin effect on U. S. consumer's brand personality perception of automobiles from China and India. Multinational Business Review. Vol. 17. No. 2.

Giraldi, Janaina de Moura Engracia (2006). A influência dos valores pessoais dos consumidores no efeito país de origem: um estudo com eletrodomésticos chineses. Tese apresentada ao Departamento de Administração e Contabilidade da Universidade de São Paulo. São Paulo.

Goldsmith, Ronald \& Clark, Ronald A. (2008). An analysis of factors affecting fashion opinion leadership and fashion opinion seeking. Journal of Fashion Marketing and Management. Vol. 12. No. 3.

Hennigs, Nadine et al. (2016). Consumer desire for luxury brands: individual luxury value perception and luxury consumption. In: Looking forward, looking back: drawing on the past to shape the future of marketing. Springer International Publishing, pp. 294304.

Husic, Melika \& Cicic, Muris (2009). Luxury Consumption Factors. Journal of Fashion Marketing and Management. Vol. 13. N.2. 
Kapferer, J.-N. \& Bastien, V. (2009a). The specificity of luxury management: Turning marketing upside down. Journal of Brand Management, 16(5/6), pp. 311-322.

Kapferer, J.-N. \& Vincent, B. (2009b). The luxury Streategy: break the rules of marketing to built luxury brands. London: Kogan Page.

Kapferer, Jean-Noel \& Valette Florence, Pierre (2016). Beyond rarity: the path of luxury desire how luxury brands grow yet remain desirable. Journal of Product \& Brand Management, vol. 25, n. 2.

Kardes, Frank R. (2002). Consumer behavior and managerial decision making. Saddle River: Prentice Hall.

Lipovetsky, Gilles \& Roux, Elyette (2005). Luxo Eterno: da idade do sagrado ao tempo das marcas. São Paulo: Cia Brasileira de Letras.

Liu, Matthew T.; Huang, Yu-Ying \& Minghua, Fiang (2007). Relations among attractiviness of endorsers, match-up, and purchase intention in sport Marketing in China. Journal of Consumer Marketing. Vol. 24.

Liu, Sindy et al. (2016). The standardization-localization dilemma of brand communications for luxury fashion retailers' internationalization into China. Journal of Business Research, vol. 69, n. 1, pp. 357-364.

Malhotra, Naresh K. (2005). Pesquisa de marketing. São Paulo: Prentice Hall.

Meirelles, F. D. S., Strehlau, V. I., \& Lopes, E. L. (2016). A Influência do País de Origem na Escolha de Marcas Desconhecidas: Uma Investigação sobre os Atributos de Marca de Materiais Esportivos. REMark, vol. 15, n.1, pp. 57-75.

Micu, Camelia; Coulter, Robin \& Price, Linda (2009). How product trial alters the effects of model attractiveness. Journal of Advertising. Vol. 38.

Okonkwo, U. (2007). Luxury fashion branding: trends, tactics, techniques. New York: Palgrave Macmillan.

Shukla, Paurav; Singh, Jaywant \& Banerjee, Madhumita (2015). They are not all same: variations in Asian consumers' value perceptions of luxury brands. Marketing Letters, vol. 26, n. 3, pp. 265-278.

Soh, Hyeonjin; Reid, Leonard \& King, Karen W. (2009). Measuring trust in advertising: development and validation of ADTRUSTscale. Journal of Advertising. Vol. 38 .

Sohail, M. Sadiq (2005). Malasyan consumer's evaluation of products made in Germany: the country of origin effect. Asia Pacific Journal of Marketing and Logistics. Vol. 17. No. 1.

Strehlau, Suzane (2008). O marketing do luxo. São Paulo: Cengage Learnig. 
. \& Huertas, Melby Zuniga (2006). Propaganda de artigos de luxo e não luxo: uma análise de conteúdo comparativa. Anais do XXX Enanpad. Salvador.

; Lopes, E. L. \& Freire, Otavio (2012). Brand Luxury Index: avaliação de um instrumento para gestão do luxo da marca. In: EMA $2012-5^{\circ}$ Encontro da Divisão de Marketing da Anpad, Curitiba/PR. EMA 2012.

Sung, Yongjun et al. (2015). Dimensions of luxury brand personality: Scale development and validation. Psychology \& Marketing, vol. 32, n. 1, pp. 121-132.

Thomas, Dana (2008) Deluxe: como o luxo perdeu o brilho (1a ed.). Rio de Janeiro: Elsevier.

Van Osselaer, Stijn M. J. \& Janiszewski, Chris (Set. 2001). Two ways of learning brand associations. Journal of Consumer Research. Vol. 28.

Verlegh, P.W. J. \& Steenkamp, J. E. M. (1999). A review and meta-analysis of country-of-origin research. Journal of Economic Psycology. Vol. 20 Issue 5.

Vigneron, Franck \& Johnson, Lester W. (2004). Measuring the perceptions of brand luxury. Journal of Brand Management. Vol 11, No. 6.

Wang, Alex \& Lin, Carolyn (2011). Effects of content class with endorsement and information relevancy on purchase intention. Management Research Review. Vol. 34

Wiedmann, K.-P. \& Nadine, H. (2013). Placing Luxury Marketing on the research Agenda not only for the Sake of Luxury - An introduction. In: K.-P. Wiedmann, \& H. Nadine, Luxury Marketing: A challenge for theory and practice (p. 416). Wiesbaden: Springer Gabler.

Yassin, N.; Noor, M. \& Mohamad O. (2007). Does image of country-of-origin matter to brand equity? Journal of Product and Brand Management. Vol. 16, No.1.

Yu, Guy-Chang; Park, Woo-Sung \& Cho, Yung-Ho (2007). MNC's HRM strategy and country of origin effect: do north american, european, and japanese firms really differ? Management Review.Vol. 18. No.4.

${ }^{i}$ Cada grupo de estudantes foi utilizado uma única vez. 